\title{
Treatment with Non-invasive respiratory support in severe COVID-19: Clinical effectiveness observational study
}

\author{
Gonzalo Segrelles-Calvo'*, Estefanía Llopis-Pastor', Glauber Ribeiro de Sousa Araújo², Inés Escribano', \\ Esther Antón', Laura Rey', Nestor Rodriguez Melean', Marta Hernández', Javier Carrillo', Celia Zamarro', \\ Mercedes García-Salmones', Susana Frases² \\ 'Respiratory Intermediate Care Unit, Respiratory Department, University Rey Juan Carlos Hospital, Madrid, Spain \\ ${ }^{2}$ Laboratorio de Biofísica de Fungos, Instituto de Biofísica Carlos Chagas Filho, Universidade Federal do Rio de Janeiro, Brasil
}

\section{Article Info}

\section{Article Notes}

Received: June 30, 2021

Accepted: September 30, 2021

\section{*Correspondence:}

Dr. Gonzalo Segrelles-Calvo, Department of Pneumology, University Rey Juan Carlos Hospital, Madrid, Spain; Email: gsegrelles@hotmail.com

(c) 2021 Segrelles-Calvo G. This article is distributed under the terms of the Creative Commons Attribution 4.0 International License.

\section{Keywords}

COVID-19

Continuous positive airway pressure

Respiratory care units

Acute respiratory failure

\section{Abstract}

Introduction: The study aimed to analyse the clinical response and shortterm outcomes with the use of high-flow oxygen therapy (HFOT), non-invasive mechanical ventilation (NIMV) with bilevel positive airway pressure, or continuous positive airway pressure (CPAP) in severe COVID-19 patients.

Methods: We conducted an observational, prospective, single-center study, approved by Ethics Committee of "Instituto de Investigación Sanitaria Fundación Jiménez Díaz” (EO102-20-HRJC).

We included a total of 130 patients $\geq 18$ years-old, with proved SARSCoV-2 infection and secondary Acute Respiratory Failure (ARF) that required treatment with Non-invasive Respiratory Support (NIRS). We collected data about population demographic characteristics, clinical factors, and evolution during the incoming. A baseline of patients treated with HFO, CPAP and NIMV were compared with one-way ANOVA test, while categorical variables were expressed as numbers and percentages and were compared using the chisquare test or Fisher's exact test when appropriate.

Results: The cohort was distributed as follows: CPAP 54.6\% ( $n=71)$, NIMV $30 \%(n=39)$, HFO $15.4 \%(n=20)$. There were no differences between NIRS subgroups regarding age, comorbidity, or functional status. At the beginning of NIRS treatment, $\mathrm{PaO}_{2} / \mathrm{FiO}_{2}$ value was $149.3 \pm 69.7$. After 24 hours, $\mathrm{PaO}_{2} / \mathrm{FiO}_{2}$ was significantly higher in the CPAP group (CPAP vs NIMV, $p$-value $=0.0042$; CPAP vs HFO, $p$-value $=0.000169$ ). The overall ICU admission evaded rate was $69.1 \%$ and TF rate was $43.8 \%$, without differences between the three therapies ( $p$-value $=0.281)$. The mortality rate was $37.2 \%$, without significant differences between subgroups.

Conclusions: Our data suggest that CPAP versus treatment with NIMV or $\mathrm{HFO}$ improves $\mathrm{PaO}_{2} / \mathrm{FiO}_{2}$ rate in severe ARF patients, significantly reducing ICU admission. No differences were observed in mortality or therapeutic failure.

\section{Introduction}

The coronavirus disease 2019 (COVID-19) is caused by the Severe Acute Respiratory Syndrome Coronavirus 2 (SARS-CoV-2), which primarily targets the respiratory tract, causing widespread inflammation in the lungs, which leads to Acute Respiratory Distress Syndrome (ARDS) in severe cases ${ }^{1}$. Approximately $14 \%$ of all people with COVID-19 develop severe respiratory disease with hypoxemic respiratory failure, and a further $5 \%$ will become critically unwell, many of whom will require intensive care ${ }^{2}$. Treatment of Acute Respiratory Failure (ARF) due to viral infection with Non-invasive Respiratory Support (NIRS) is open to discussion. Previous studies 
showed a high failure rate in patients treated with NonInvasive Mechanical Ventilation (NIMV), 30\% in SARSCoV-1 and $13-77 \%$ in Influenza A H1N1 outbreaks ${ }^{3}$. The patient with pneumonia by Influenza A H1N1 treated with High Flow Oxygen therapy (HFO) has been reported a success rate of $39 \%{ }^{4}$. There is currently no information available on the effectiveness of NIRS, neither the best subtype of therapy used to treat ARF in severe COVID-19. The European and American Respiratory Societies practice guideline recommended NIMV as a preventive strategy for avoiding intubation in hypoxemic ARF, when performed by experienced teams, in highly selected cooperative patients ${ }^{5}$. The Spanish Respiratory Society recommended the use of NIRS as "bridge therapy" in cases of ARF again, without late admission to the ICU and with a preference for HFO. Despite this, the course of the COVID-19 pandemic has changed previous knowledge and brought the NIRS to the front line-therapy.

Our hypothesis was that early use of NIRS in severe COVID-19 improves clinical outcomes and short-term prognostic.

The aim of the study was to present our clinical experience treating severe COVID-19 patients with NIRS [HFO, NIMV or (CPAP)] and compare clinical outcomes between the three subgroups of treatment. Our secondary endpoint was to analyse factors associated with therapeutic failure.

\section{Patients and Methods}

\section{Study design}

We conducted an observational, prospective, singlecentre study at Hospital Universitario Rey Juan Carlos (HURJ) during the period from $1^{\text {st }}$ February to $30^{\text {th }}$ June 2020.

HRJC is a public hospital in the town of Móstoles, located in the south of the region of Madrid, Spain. The hospital provides care to patients residing in Móstoles and 18 other municipalities nearby, totalling 178,000 inhabitants. The hospital has 292 single and 18 double rooms, an intensive care unit (ICU) with 27 beds, and a postoperative recovery area for up to 48 patients. The Pneumology Department (PD) has a hospitalization area, and four rooms of Respiratory Intermediate Care Unit (RICU) integrated the ICU.

During the pandemic, PD reorganized its structure to prioritize the care of COVID-19 patients.

This study was carried out according to principles of Helsinki's Declaration and was approved by the Ethics Committee of "Instituto de Investigación Sanitaria Fundación Jiménez Díaz" (E0102-20-HRJC). The Ethics Committee waived the need for consent.

\section{Population of the study}

We included all patients $\geq 18$ years old, with proved SARS-CoV-2 infection ${ }^{6}$ with secondary ARF and that required treatment with NIRS. Based on all cases, the Pneumologist either in our RICU or in Internal Medicine Department directly initiated NIRS.

We excluded patients that only received conventional oxygen therapy treatment or when NIRS was prescribed by the ICU or Anaesthesia Service and not evaluated by PD. We also excluded patients when dates could not be collected; when patients refused the treatment or when NIRS was used for weaning process and not in the acute setting.

SARS-CoV-2 diagnostic was performed in all patients with RT-PCR ("Primerdesign Ltd COVID-19 genesig $®$ RealTime PCR assay", HAIN Lifescience, Chandler's Ford, UK). The serological test was made in patients with concordant clinical settings and two negative RT-PCR determinations, with COVID-19 rapid test Biozek Medical (BIOZEK, Apeldoorn, Netherlands).

\section{Data collection}

Our outcomes included 1) change in $\mathrm{PaO}_{2} / \mathrm{FiO}_{2}$ after 24 hours, 2) ICU admission rate, 3) therapeutic failure (change of NIRS, ICU admission, and death), and 4) mortality rate. To respond to the outcomes, we collected clinical, radiological, and laboratory data from electronic medical records. Missing data were not imputed.

We collected data about demographic characteristics (age, gender, institutionalized patient, presence of frailty criteria $^{7}$ or comorbidities), clinical factors (COVID-19 symptoms, time from started symptoms to incoming, medical treatment, pneumonia severity index ${ }^{8}$, radiological severity injure ${ }^{9}$, information about NIRS (subgroup of therapy, clinical or gasometric criteria to start NIRS, HACOR $^{10}$ and ROX index ${ }^{11}$, therapy failure and ICU admitted rate) and evolution during incoming (presence of major complication, admitted days, mortality rate).

Therapeutic failure (TF) is considered as clinical worsening that leads to change the therapy, ICU admission or/and to the death of the patient.

\section{Statistical analysis}

No statistical sample size assessment was performed a priori, and the sample size was the number of patients treated during the study period $(n=130)$ in our centre.

A baseline of patients treated with HFO, CPAP and NIMV were compared. Across the treatment subgroups, continuous variables were expressed as means and standard deviation $( \pm$ SD) and were compared with one-way ANOVA test, while categorical variables were expressed as numbers and percentages (\%) and were 
compared using the chi-square test $\left(\chi^{2}\right)$ or Fisher's exact test when appropriate. Percentages of available data for the overall study population were based on the total number of patients included in the study, while the distribution of available data over the treatment subgroups was based on the available data over for that variable, and the percentages were calculated using the number of available data for that subgroup.

Logistic regression was applied to investigate the relationship between subgroups of NIRS and outcomes (TF and mortality rate). All the outcomes have been assessed by intention-to-treat analysis.

For all tests, a two-sided of 0.05 value was considered significant. The statistical analysis was performed with SPPS version 20.0 (SPSS Inc., Chicago, IL, USA) software.

\section{Results}

Over the whole study period, we recruited 215 patients, and 130 of them fulfilled the inclusion criterion (Figure 1). The cohort was distributed according to the therapy used as follows: CPAP $54.6 \%(n=71)$, NIMV $30 \%(n=39)$, HFO $15.4 \%(n=20)$. There were no differences between NIRS subgroups regarding age, comorbidity, or functional status (Table 1).

Therapeutic ceiling allocation was: $63.1 \%$ ICU, $22.3 \%$ RICU and $14.6 \%$ no ICU and RICU admission candidate.

At the beginning of NIRS treatment, $\mathrm{PaO}_{2} / \mathrm{FiO}_{2}$ value was $149.3 \pm 69.7$, and $85.4 \%(n=111)$ presented $\mathrm{PaO}_{2} / \mathrm{FiO}_{2} \leq$ 200. After 24 hours, $\mathrm{PaO}_{2} / \mathrm{FiO}_{2}$ was significantly higher in the CPAP group compared with the NIMV and HFO group [CPAP vs NIMV, $p$-value $=0.0042, \mathrm{CI}_{95 \%}(0.98,66.56)$ and

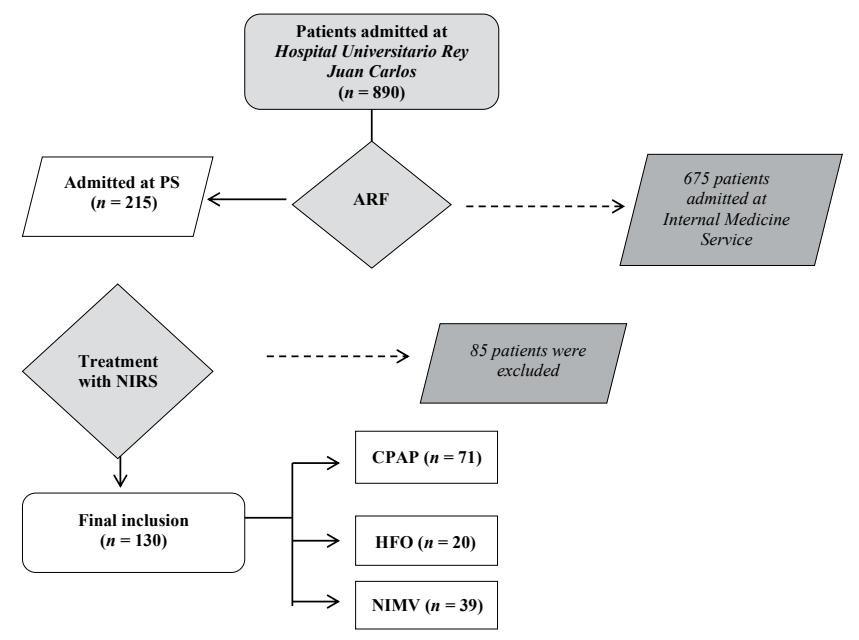

HRJC: Hospital Universitario Rey Juan Carlos, PS: Pneumology Service, CPAP: Continuous Positive Airway Pressure, HFO: High Flow Oxygen Therapy, NIVM: Non-invasive Mechanical Ventilation, NIRS: Non-invasive Respiratory Support.

Figure 1: Flow-chart. At the study period, 215 patients were admitted at Respiratory service, 130 of whom fulfilled inclusion criteria.
Table 1: We summarize the previous basal situation, clinical COVID-19 presentation, and prescribed treatment. Comparison between treatment groups and the existence of significant differences are also provided.

\begin{tabular}{|c|c|c|c|}
\hline & $\begin{array}{c}\text { CPAP } \\
(n=71)\end{array}$ & $\begin{array}{c}\text { HFO } \\
(n=20)\end{array}$ & $\begin{array}{c}\text { NIMV } \\
(n=39)\end{array}$ \\
\hline Males & $46(65)$ & $16(80)$ & $26(67)$ \\
\hline $\begin{array}{l}\text { Age years } \\
>70 \text { years old }\end{array}$ & $\begin{array}{c}65.5 \pm 12.7 \\
33(46.5)\end{array}$ & $\begin{array}{c}57.2 \pm 13.6^{*} \\
7(35)\end{array}$ & $\begin{array}{c}65.9 \pm 11.9 \\
17(43.6)\end{array}$ \\
\hline $\begin{array}{l}\text { Frail Index (Max : Min) } \\
\qquad \mathrm{Fl}>4\end{array}$ & $\begin{array}{l}2(6: 1) \\
7(9.9)\end{array}$ & $\begin{array}{c}1.45(4: 1) \\
1(5)\end{array}$ & $\begin{array}{l}2,31(7: 1) \\
7(17.9)\end{array}$ \\
\hline Institutionalized & $3(4.2)$ & 0 & $7(17.9)^{*}$ \\
\hline Charlson Index & $2.7 \pm 3.1$ & $2.3 \pm 3.1$ & $3.9 \pm 3.2$ \\
\hline $\begin{array}{l}\text { Comorbidity } \\
\text { Hypertension } \\
\text { Obesity } \\
\text { Dyslipidemia } \\
\text { Sleep apnea syndrome } \\
\text { COPD/Asthma } \\
\text { Hypothyroidism }\end{array}$ & $\begin{array}{l}56(78.9) \\
45(63.4) \\
24(33.8) \\
16(22.5) \\
10(14.1) \\
11(15.5) \\
8(11.3)\end{array}$ & $\begin{array}{l}15(75) \\
11(55) \\
6(30) \\
5(25) \\
1(5) \\
3(15) \\
2(10)\end{array}$ & $\begin{array}{c}33(84.6) \\
20(51.3) \\
15(38.5) \\
10(25.6) \\
15(38.5)^{*} \\
10(25.7) \\
4(10.3)\end{array}$ \\
\hline $\begin{array}{l}\text { Respiratory therapy at home } \\
\text { Oxygen therapy } \\
\text { CPAP } \\
\text { NIM }\end{array}$ & $\begin{array}{c}1(1.4) \\
10(14.1) \\
0\end{array}$ & $\begin{array}{c}0 \\
1(5) \\
0\end{array}$ & $\begin{array}{c}0 \\
8(20.5)^{*} \\
4(7.7)^{*}\end{array}$ \\
\hline $\begin{array}{l}\text { Admitted at } \\
\text { RICU } \\
\text { Internal Medicine Unit }\end{array}$ & $\begin{array}{l}43.7 \\
56.3\end{array}$ & $\begin{array}{l}65 \\
35\end{array}$ & $\begin{array}{l}46.2 \\
53.8\end{array}$ \\
\hline $\begin{array}{l}\text { Symptoms } \\
\text { Onset of symptoms (days) } \\
\text { Cough } \\
\text { Fever } \\
\text { Chest pain } \\
\text { Dyspnea } \\
\text { Diarrhea } \\
\text { Myalgia }\end{array}$ & $\begin{array}{c}8.1 \pm 4 \\
58(81.7) \\
64(90.1) \\
9(12.7) \\
55(77.5) \\
15(21.1) \\
6(8.5)\end{array}$ & $\begin{array}{c}7.7 \pm 4 \\
15(75) \\
18(90) \\
5(25) \\
12(60) \\
4(20) \\
3(15)\end{array}$ & $\begin{array}{l}8.7 \pm 10.5 \\
33(84.6) \\
29(74.4) \\
3(7.7) \\
33(84.6) \\
8(20.5) \\
4(10.3)\end{array}$ \\
\hline $\begin{array}{l}\text { COVID-19 treatment } \\
\text { Antibiotic } \\
\text { Azithromycin } \\
\text { Hydroxychloroquine } \\
\text { Lopinavir/Ritonavir } \\
\text { Corticosteroids } \\
\text { Cyclosporine } \\
\text { Tocilizumab }\end{array}$ & $\begin{array}{l}71(100) \\
66(93) \\
70(98.6) \\
23(32.4) \\
68(95.8) \\
8(11.3) \\
24(33.8)\end{array}$ & $\begin{array}{c}20(100) \\
19(95) \\
20(100) \\
7(35) \\
16(80) \\
1(5) \\
9(45)\end{array}$ & $\begin{array}{c}39(100) \\
36(92.3) \\
37(94.9) \\
7(17.9) \\
32(82.1) \\
5(12.8) \\
14(35.9)\end{array}$ \\
\hline
\end{tabular}

Data present as mean (Standard Deviation, SD) or $\mathrm{n}(\%)$, and results expressed as rate are presented as \%, unless otherwise indicated. ${ }^{*} p$-value $<0.05$. In comorbidities and COVID-19 symptoms we only included the items with a prevalence $>10 \%$. In the case of sleep apnea syndrome, we considered moderate-to-severe cases. CPAP: Continuous Positive Airway Pressure, HFO: High Flow Oxygen Therapy, NIVM: Non-invasive mechanical ventilation, Max: Maximum, Min: Minimum, FI: Frail Index, RICU: Respiratory Intermediate Care Unit, COPD: Chronic Obstructive Pulmonary Disease.

CPAP vs HFO, $p$-value $\left.=0.000169, \mathrm{CI}_{95 \%}(25.98-89.56)\right]$. The increase of $\mathrm{PaO}_{2} / \mathrm{FiO}_{2}$ at 24-hours was higher in the patients treated with CPAP $(\Delta 44.3)$, followed by patients treated with NIMV $(\Delta 25.6)$ and, finally, patients treated with HFO $(\Delta 16.3)$, $p$-value $=0.043$.

The overall ICU admission rate was 30.9\% (CPAP group 
$24.4 \%$ vs HFO and NIMV group with $37.5 \%$ both, $\chi^{2}=3.18$, p-value $=0.045, \quad$ IC $\left._{95 \%}(0.220-0.241)\right)$. Our calculated $\mathrm{TF}$ rate was $43.8 \%$. We measured this result in different scenarios, the first one according to admission setting (RICU vs Internal Medicine Unit) and the second by NIRS subgroup therapy. In the first scenario, TF was 34\% in admitted at RICU vs $53 \%$ of those admitted at the Internal Medicine Unit $\left[\chi^{2}=4.79, p\right.$-value $\left.=0.029, \mathrm{CI}_{95 \%}(1.03-1.91)\right]$. According to the subgroup of NIRS, in patients treated with CPAP TF rate was $39.2 \%$, in HFO group $46.1 \%$ and, finally, in NIMV group was $53.8 \%$ ( $p$-value $=0.281)$. The Rox index Odds Ratio (OR) $=0.71, \mathrm{CI}_{95 \%}(0.473-0.813)$, $p$-value $\left.=0.01\right)$, age $\left(\mathrm{OR}=1.06, \mathrm{CI}_{95 \%}(1.017-1.105), \quad p\right.$-value $\left.=0.06\right)$, comorbidity $\left(\mathrm{OR}=5.354, \mathrm{CI}_{95 \%}(1.330-21.547)\right.$, $p$-value $=0.018)$ and secondary infection $\left(\mathrm{OR}=13.551, \mathrm{CI}_{95 \%}\right.$ (3.312 - 55.446), $p$-value $=0.000288$ ) were the independent risks factors associated with TF. Approximately, $\sim 13 \%$ of cases $(n=17)$ we changed therapy because not get a clinical response. Mainly, the therapy change was to NIMV (81.3\%, $p$-value $=0.00001)$. In CPAP group we changed therapy about $21 \%$ and only in the $10 \%$ of HFO group $\left[\chi^{2}=10.08, p\right.$-value $\left.=0.006, \mathrm{CI}_{95 \%}(0.005-0.009)\right]$. We tried to determinate the influence of time-delayed in the starting therapy, but we not found differences between groups
(CPAP group $11.74 \pm 4.7$ days vs HFO group $10.67 \pm 6.1$, $p$-value $=0.229$ ).

The mortality rate was $37.2 \%$, without significant differences between subgroups of the NIRS treatment after adjustment for confounder (Table 2). The odds ratios (ORs) for in-hospital COVID-19 related death were $9.83\left(\mathrm{CI}_{95 \%}\right.$ $2.51-38.44$ ) in people $>70$ years old and $\mathrm{OR}=48.003$ $\left(\mathrm{CI}_{95 \%} 12.023\right.$ - 191.65) for patients with TF. Other variables as Frail index, comorbidities, $\mathrm{PaO}_{2} / \mathrm{FiO}_{2}<200$ or subgroup of NIRS were not related to mortality in our model.

\section{Discussion}

In severe COVID-19 disease, lung injury can become a high mortality complication. Recently, WANG D et al. ${ }^{12}$ established the rate of ICU admission and need for respiratory support in COVID-19 26\%. Previous recommendations suggested avoiding the use of NIRS in patients with $\mathrm{ARF}^{13}$. Nevertheless, in the current COVID-19 pandemic, NIRS has been shown as a safe, feasible, and helpful treatment ${ }^{14}$. The fact, European Respiratory Society recommended their use, even in severe patients ${ }^{15}$. The pattern of NIRS usage is very widely between research ${ }^{16}$, and there is no evidence about which subtype of NIRS (CPAP, HFO or NIMV) should be used first ${ }^{17}$. In our cohort, $14.6 \%$

Table 2: The differences in the clinical/functional indication of NIRS and the clinical response among the study groups are showing

\begin{tabular}{|c|c|c|c|}
\hline & $\operatorname{CPAP}(n=71)$ & HFO $(n=20)$ & $\operatorname{NIMV}(n=39)$ \\
\hline Days between the onset of symptoms until initiated NIRS treatment & $11.7 \pm 4.7$ & $10.7 \pm 6$ & $11 \pm 10.8$ \\
\hline \multicolumn{4}{|l|}{$\begin{array}{l}\text { NIRS indications: } \\
\text { Gasometrical criteria }\end{array}$} \\
\hline $\mathrm{PaO}_{2} / \mathrm{FiO}_{2}<200$ & 44.2 & 16.7 & 9 \\
\hline Hypoxemic ARF & 55.8 & 83.3 & $84.2^{*}$ \\
\hline Respiratory acidosis & 0 & 0 & $6.8^{*}$ \\
\hline \multicolumn{4}{|l|}{ Clinical criteria } \\
\hline Severe dyspnea & 30.2 & 16.7 & 26.3 \\
\hline Tachypnoea & 0 & 0 & 10.5 \\
\hline Work of breath & 16.3 & 0 & 5.3 \\
\hline$\geq 2$ previous criteria & 44.2 & 61.1 & 52.6 \\
\hline $\begin{array}{l}\mathrm{PaO}_{2} / \mathrm{FiO}_{2} \text { at beginning of treatment } \\
\mathrm{PaO}_{2} / \mathrm{FiO}_{2} \leq 200\end{array}$ & $\begin{array}{l}158.4 \pm 75 \\
55(77.5)\end{array}$ & $\begin{array}{l}128.7 \pm 61 \\
19(95)\end{array}$ & $\begin{array}{c}143.4 \pm 62.3 \\
33(84.6)\end{array}$ \\
\hline $\begin{array}{l}\mathrm{PaO}_{2} / \mathrm{FiO}_{2} \text { after } 24 \text { hours of treatment } \\
\text { Increase } \mathrm{PaO}_{2} / \mathrm{FiO}_{2} \\
\text { iRox } \\
\text { Ihacor }\end{array}$ & $\begin{array}{c}202.7 \pm 70 \\
44.3^{*} \\
4.3 \pm 2 \\
4.6 \pm 2.5\end{array}$ & $\begin{array}{l}145 \pm 26 \\
16.3 \\
3.7 \pm 1.6 \\
5.4 \pm 2.3\end{array}$ & $\begin{array}{c}169 \pm 30 \\
25.6 \\
3.6 \pm 2 \\
6.3 \pm 3.4^{*}\end{array}$ \\
\hline $\begin{array}{l}\text { NIRS parameters } \\
\text { IPAP }\left(\mathrm{cmH}_{2} \mathrm{O}\right) \\
\text { EPAP }\left(\mathrm{cmH}_{2} \mathrm{O}\right) \\
\text { Flow }(\mathrm{lpm}) \\
\mathrm{FiO}_{2}(\%)\end{array}$ & $\begin{array}{c}- \\
10 \\
- \\
50\end{array}$ & $\begin{array}{c}- \\
- \\
54 \\
91^{*}\end{array}$ & $\begin{array}{c}16 \\
9.5 \\
- \\
70\end{array}$ \\
\hline $\begin{array}{l}\text { Therapeutic failure rate } \\
\text { ICU admitted after TF rate } \\
\text { Mortality rate } \\
\text { Change therapy }\end{array}$ & $\begin{array}{c}39.2 \\
10(14) \\
24(33.8) \\
15(21)\end{array}$ & $\begin{array}{l}46.1 \\
6(30) \\
7(35) \\
2(10)\end{array}$ & $\begin{array}{c}53.8 \\
9(23) \\
14(35.8) \\
0\end{array}$ \\
\hline
\end{tabular}

Data present as mean (Standard Deviation, SD) or $\mathrm{n}(\%)$, and results expressed as rate are presented as \%, unless otherwise indicated. ${ }^{*} p$-value <0.05. CPAP: Continuous Positive Airway Pressure, HFO: High Flow Oxygen Therapy, NIMV: Non-invasive mechanical ventilation, RICU: Respiratory Intermediate Care Unit, NIRS: Non-invasive Respiratory Support, iROX: ROX index, iHACOR: HACOR index, IPAP: Inspiratory Airway Pressure, EPAP: Expiratory Airway Pressure, ICU: Intensive Care Unit, TF: Therapeutic Failure. 
need treatment with NIRS, mainly with CPAP (54.6\%). The efficacy of NIRS in these cases remains dark, but it seems unethical to conduct a randomized study to compare treated versus untreated patients with the information from previously published observational studies. Two recent studies confirmed the effectiveness of CPAP as the first choice of treatment, avoiding intubation ${ }^{18,19}$. The studies fashioned in preceding viral pandemics [SARSCoV-1 and Influenza A (H1N1)] showed at a high rate of TF and mortality. Classically TF has been defined as the disability of the NIRS to avoid ICU admission and intubation to provide invasive mechanical ventilation ${ }^{20}$. Most of these studies are heterogeneous, and their results are difficult to compare. In the current SARS-CoV-2 outbreak, the cases series published estimates a TF rate of $76 \%{ }^{21}$. These results duplicate our global $\mathrm{TF}$, found in $43.8 \%$. In the logistic regression, the main factors that explained our $\mathrm{TF}$ rate were age $(O R=1.060)$, $i R o x(O R=0.71)$, comorbidity $(O R$ $=5.354)$ and secondary infection $(\mathrm{OR}=13.551)$. Moreover, TF was significantly lower in patients admitted at RICU than those admitted at conventional hospitalization (34\% vs $53 \%$, $p$-value $=0.029$ ). In our opinion, we counted with specialized RICU allowed continuous patient monitoring and early detection of TF signs. Besides this, all health workers in our Unit are highly specialized in the use of NIRS. Therefore, we considered the main reasons that could explain our results. We also detected a high TF rate in the NIMV group (53.8\%). In the case of NIMV, some observational studies showed that NIMV was associated with a higher overall ICU mortality ${ }^{22}$, especially in those patients with lower $\mathrm{PaO}_{2} / \mathrm{FiO}_{2}{ }^{23}$. Despite that was not a primary or secondary endpoint in our study, we thought that the used of NIMV in patients with previous severe illness (severe COPD, obesity hypoventilation, neuromuscular diseases, etc.) or as rescue therapy when others NIRS fault, could explain high mortality associated to their use. In any case, our TF described in patients treated with NIMV was remarkably like the failure rates reported in previous outbreaks of SARS, MERS, and Influenza $\mathrm{A}^{24}$.

In our cohort, patients treated with CPAP were admitted to ICU and started IMV in the $24.4 \%$ vs $37.5 \%$ in patients treated with HFO or with NIMV, $p$-value $=0.05$. The CPAP group also improved $\mathrm{PaO}_{2} / \mathrm{FiO}_{2}$ value at 24 hours to start the treatment (CPAP vs NIMV $p$-value $=0.042$ and CPAP vs HFO $p$-value $=0.0000169$ ). The gradient of increase of $\mathrm{PaO}_{2} /$ $\mathrm{FiO}_{2}$ was higher in CPAP-group ( $\Delta 44.3$ ), followed by NIMV $(\Delta 25.6)$ and, finally, patients treated with HFO ( $\Delta$ 16.3), $p$-value $=0.043$. These results are supported by other recent studies that have shown that CPAP avoids intubations and ICU admissions in COVID-19 patients ${ }^{18,19}$. Presumably, the CPAP mechanism of action plays a role in these observations. CPAP supplies continuous support pressure along the respiratory cycle that enhances alveolar recruitment, pulmonary compliance, and ventilation/perfusion imbalance.
Some European Respiratory and Intensive Care Society considered that in patients with worsening respiratory failure HFO might be useful ${ }^{5}$. At the same time, CPAP and NIMV can be used to a limited extent. Our results do not support this recommendation, assuming the limitations of our work, and they would support the use of CPAP as the treatment of choice in more severe patients. Without forgetting that the use of HFO has its indication in patients with moderate ARF due to COVID-1925.

We checked that there were no differences in mortality rate (CPAP 33.8\%, HFO 35\%, and NIMV 35.8\%, $p$-value $=0.915)$ or TF (38\% CPAP vs $53.8 \%$ in NIMV group and $45 \%$ in HFO, $p$-value $=0.281$ ), but in both cases, the CPAP group had a better outcome. For these reasons, our preliminary results support the choice of CPAP as the first treatment. Obviously, more studies are needed to confirm this recommendation.

Our mortality rate was explained by age $(\mathrm{OR}=9.83$ in patients $>70$ years old), but above all, for the TF rate (OR = 48.003). The risk of severe illness in adults increases with age, with older people at the highest risk $^{26}$. In older, we thought that frailty and comorbidities were the principal factors that explained poor outcomes. Studies aimed at older people could help us to make decisions in the future and improve results in those elderly that benefit more from NIRS treatment.

When we started treatment with CPAP, we were more likely to change therapy than if we chose HFO. The time from the onset of symptoms to the start of treatment did not explain the outcome, but the fact that outside the ICU, CPAP was frequently used in an unmonitored setting could be a reason for our observations. Although other works such as that of FRANCO C et al. ${ }^{27}$ demonstrated that NIRS could help treat severely affected COVID-19 patients outside of the ICU. We think further studies are needed to confirm these observations, verify the most effective NIRS subset, and investigate the causes of FT.

\section{Conclusions}

The present study is one of the first on real-life NIRS treatment of the COVID-19 pandemic and, to our knowledge, the first in Spain.

We assume the existence of several weaknesses, as it is an observational study; we contrast groups that are not always comparable. The choice of NIRS could be biased by limited access to devices during the peaks of the pandemic. Nevertheless, we considered that these limitations did not disturb our aim of describing the results in a real setting.

In our experience, CPAP was the most widely used therapy, with better outcomes defined as a lower rate of ICU admission. Without a doubt, we need more information about other experiences to unify the results and draw the best conclusions. 


\section{Ethics Declaration}

The present study was approved by the Ethics Committee of the Fundación Jiménez Díaz Health Research Institute (E0102-20-HRJC). In view of the pandemic situation, informed consent was not requested from the patients. Personal information and data obtained from the subjects were kept confidential.

\section{Transparency Declaration}

The authors declare that they have no known competing financial interests or personal relationships that could have appeared to influence the work reported in this paper.

\section{Acknowledgement}

This work was supported by the Brazilian agencies Conselho Nacional de Desenvolvimento Científico e Tecnológico (CNPq), Coordenação de Aperfeiçoamento de Pessoal de Nível Superior (CAPES) - Finance Code 001 and Fundação Carlos Chagas Filho de Amparo à Pesquisa do Estado do Rio de Janeiro (FAPERJ).

\section{References}

1. Varghese GM, John R, Manesh A, et al. Clinical Management of COVID-19. Indian J Med Res. 2020; 151(5): 401-410. doi:10.4103/ ijmr.IJMR_957_20

2. Wu Z, McGoogan JM. Characteristics of and important lessons from the Coronavirus Disease 2019 (COVID-19) outbreak in China. JAMA. 2020; 323(13): 1239. doi:10.1001/jama.2020.2648

3. Masclans JR, Pérez M, Almirall J, et al. Early non-invasive ventilation treatment for severe influenza pneumonia. Clin Microbiol Infect. 2013; 19(3): 249-256. doi:10.1111/j.1469-0691.2012.03797.x

4. Kumar A. Critically ill patients with 2009 influenza A(H1N1) infection in Canada. JAMA. 2009; 302(17): 1872. doi:10.1001/jama.2009.1496

5. Cinesi Gómez C, Peñuelas Rodríguez Ó, Luján Torné M, et al. Recomendaciones de consenso respecto al soporte respiratorio no invasivo en el paciente adulto con insuficiencia respiratoria aguda secundaria a infección por SARS-CoV-2. Rev Esp Anestesiol Reanim 2020; 67(5): 261-270. doi:10.1016/j.redar.2020.03.006

6. Ministerio de Sanidad. Interpretación de las pruebas diagnósticas frente a SARS-CoV-2. April 24, 2020. Published 2020. Accessed July 10, 2020. https://www.mscbs.gob.es/profesionales/saludPublica/ ccayes/alertasActual/nCov-China/documentos/INTERPRETACION_ DE_LAS_PRUEBAS.pdf

7. Kim DH, Schneeweiss S, Glynn RJ, et al. Measuring frailty in medicare data: development and validation of a claims-based frailty index. Journals Gerontol - Ser A Biol Sci Med Sci. 2018; 73(7): 980-987. doi:10.1093/gerona/glx229

8. Kim MA, Park JS, Lee CW, et al. Pneumonia severity index in viral community acquired pneumonia in adults. PLoS One. 2019; 14(3): e0210102. doi: 10.1371/journal.pone.0210102

9. Francone M, Iafrate F, Masci GM, et al. Chest CT score in COVID-19 patients: correlation with disease severity and short-term prognosis. Eur Radiol. 2020; 30(12): 6808-6817. doi:10.1007/s00330-02007033-y

10. Duan J, Han X, Bai L, et al. Assessment of heart rate, acidosis, consciousness, oxygenation, and respiratory rate to predict noninvasive ventilation failure in hypoxemic patients. Intensive Care Med. 2017; 43(2): 192-199. doi:10.1007/s00134-016-4601-3
11. Roca O, Messika J, Caralt B, et al. Predicting success of high-flow nasal cannula in pneumonia patients with hypoxemic respiratory failure: The utility of the ROX index. J Crit Care. 2016; 35: 200-205. doi:10.1016/j.jcrc.2016.05.022

12. Wang D, Hu B, Hu C, et al. Clinical characteristics of 138 hospitalized patients with 2019 novel Coronavirus - Infected pneumonia in Wuhan, China. JAMA. 2020; 323(11): 1061. doi:10.1001/ jama.2020.1585

13. Rochwerg B, Brochard L, Elliott MW, et al. Official ERS/ ATS clinical practice guidelines: noninvasive ventilation for acute respiratory failure. Eur Respir J. 2017; 50(2): 1602426. doi:10.1183/13993003.02426-2016

14. Sivaloganathan AA, Nasim-Mohi M, Brown MM, et al. Noninvasive ventilation for COVID-19-associated acute hypoxaemic respiratory failure: experience from a single centre. Br J Anaesth. 2020; 125(4): e368-e371. doi:10.1016/j.bja.2020.07.008

15. Chalmers JD, Crichton ML, Goeminne PC, et al. Management of hospitalised adults with coronavirus disease 2019 (COVID-19): a European Respiratory Society living guideline. Eur Respir J. 2021; 57(4): 2100048. doi:10.1183/13993003.00048-2021

16. Carpagnano GE, Buonamico E, Migliore G, et al. Bilevel and continuous positive airway pressure and factors linked to all-cause mortality in COVID-19 patients in an intermediate respiratory intensive care unit in Italy. Expert Rev Respir Med. 2021; 15(6): 853-857. doi:10.1080/1 7476348.2021.1866546

17. Procopio G, Cancelliere A, Trecarichi EM, et al. Oxygen therapy via high flow nasal cannula in severe respiratory failure caused by SarsCov-2 infection: a real-life observational study. Ther Adv Respir Dis. 2020; 14: 175346662096301. doi:10.1177/1753466620963016

18. Raharja A, Kwan JT, Billings JJ, et al. Ward-based continuous positive airway pressure (CPAP) in SARS-CoV-2. Clin Med (Northfield Il). 2021; 21(Suppl 2): 55-56. doi:10.7861/clinmed.21-2-s55

19. Nightingale R, Nwosu N, Kutubudin F, et al. Is continuous positive airway pressure (CPAP) a new standard of care for type 1 respiratory failure in COVID-19 patients? A retrospective observational study of a dedicated COVID-19 CPAP service. BMJ Open Respir Res. 2020; 7(1): e000639. doi:10.1136/bmjresp-2020-000639

20. Manso Ruiz de la Cuesta R, Modesto Alarport V, Medina Villanueva A, et al. New paediatric definition of acute respiratory distress syndrome: Only unilateral infiltrates. Are we sure about this? Medicina Intensiva. 2021; 45(5): 318-319. doi: 10.1016/j.medine.2019.09.010

21. Radovanovic D, Coppola S, Franceschi E, et al. Mortality and clinical outcomes in patients with COVID-19 pneumonia treated with noninvasive respiratory support: A rapid review. J Crit Care. 2021; 65: 1-8. doi:10.1016/j.jcrc.2021.05.007

22. Wendel Garcia PD, Aguirre-Bermeo H, Buehler PK, et al. Implications of early respiratory support strategies on disease progression in critical COVID-19: a matched subanalysis of the prospective RISC-19ICU cohort. Crit Care. 2021; 25(1): 175. doi:10.1186/s13054-02103580-y

23. Corradini E, Ventura P, Ageno W, et al. Clinical factors associated with death in 3044 COVID-19 patients managed in internal medicine wards in Italy: results from the SIMI-COVID-19 study of the Italian Society of Internal Medicine (SIMI). Intern Emerg Med. 2021; 16(4): 1005-1015. doi:10.1007/s11739-021-02742-8

24. Han F, Jiang YY, Zheng JH, et al. Noninvasive positive pressure ventilation treatment for acute respiratory failure in SARS. Sleep Breath. 2004; 8(2): 97-106. doi:10.1055/s-2004-829634

25. Vianello A, Arcaro G, Molena B, et al. High-flow nasal cannula oxygen therapy to treat patients with hypoxemic acute respiratory failure consequent to SARS-CoV-2 infection. Thorax. 2020; 75(11): 9981000. doi:10.1136/thoraxjnl-2020-214993 
26. Mazumder H, Hossain MM, Das A. Geriatric care during public health emergencies: Lessons learned from novel Corona Virus Disease (COVID-19) pandemic. J Gerontol Soc Work. 2020; 63(4): 257-258. do i:10.1080/01634372.2020.1746723
27. Franco C, Facciolongo N, Tonelli R, et al. Feasibility and clinical impact of out-of-ICU noninvasive respiratory support in patients with COVID-19-related pneumonia. Eur Respir J. 2020; 56(5): 2002130. doi:10.1183/13993003.02130-2020 